\title{
Effect of PVA-co-MMA Copolymer on the Physical, Mechanical, and Thermal Properties of Tropical Wood Materials
}

\author{
Md. Saiful Islam, ${ }^{1}$ Sinin Hamdan, ${ }^{2}$ Mansor B. Ahmad, ${ }^{1}$ Mahbub Hasan, ${ }^{3}$ \\ Azman Hassan, ${ }^{4}$ M. K. Mohamad Haafiz, ${ }^{5}$ and M. Jawaid ${ }^{6}$ \\ ${ }^{1}$ Department of Chemistry, Faculty of Science, Universiti Putra Malaysia, 43400 Serdang, Selangor, Malaysia \\ ${ }^{2}$ Faculty of Engineering, Universiti Malaysia Sarawak, 94300 Kota Samarahan, Sarawak, Malaysia \\ ${ }^{3}$ Department of Materials and Metallurgical Engineering, Bangladesh University of Engineering and Technology, \\ Dhaka 1000, Bangladesh \\ ${ }^{4}$ Department of Polymer Engineering, Faculty of Chemical Engineering, Universiti Teknologi Malaysia, 81310 Skudai, Johor, Malaysia \\ ${ }^{5}$ School of Industrial Technology, Universiti Sains Malaysia, 11800 Penang, Malaysia \\ ${ }^{6}$ Laboratory of Biocomposite Technology, Institute of Tropical Forestry and Forest Products (INTROP), \\ Universiti Putra Malaysia (UPM), 43400 Serdang, Selangor, Malaysia
}

Correspondence should be addressed to Md. Saiful Islam; msaifuli2007@gmail.com

Received 19 June 2014; Revised 13 August 2014; Accepted 13 August 2014; Published 31 August 2014

Academic Editor: Peter Chang

Copyright (C) 2014 Md. Saiful Islam et al. This is an open access article distributed under the Creative Commons Attribution License, which permits unrestricted use, distribution, and reproduction in any medium, provided the original work is properly cited.

\begin{abstract}
The present study demonstrates the effect of copolymer on the physical, mechanical, and thermal properties of tropical wood and wood polymer composites (WPCs). Mixed monomers of methyl methacrylate (MMA) and polyvinyl alcohol (PVA) were effectively impregnated into the cellular structure of several types of tropical wood, which then underwent a catalyst-thermal process to polymerize and form WPC. The manufacturing of WPC was confirmed through Fourier transform infrared (FTIR) spectroscopy and scanning electron microscopic (SEM) analysis. The SEM observation showed that polymer converted from monomers filled up wood cell cavities and tightly interacted with wood matrix. The X-ray diffraction results reveal that the degree of crystallinity was significantly improved upon impregnation with PVA-co-MMA copolymer. The modulus of elasticity (MOE) and compressive modulus were found to be significantly higher after treatment with MMA/PVA indicating improvement of mechanical properties of the wood samples. In addition, the modified WPC had lower water absorption compared to their corresponding raw samples. It is interesting to note that thermogravimetric (TGA) analysis shows an extensive improvement in thermal properties of WPC.
\end{abstract}

\section{Introduction}

Structural wood has always been an essential raw material and has been used worldwide for a variety of purposes. However, it has some disadvantages, including "poor physicomechanical properties, susceptibility to damage, deterioration, and frequent costly maintenance [1-3].” In addition, "the physical and mechanical properties of wood are readily deteriorated by environmental variation" [4], which is the main drawback and limitation of its properties. The presence of hydrophilic hydroxyl groups $(-\mathrm{OH})$ in the wood components is the main factor responsible for the negative properties. Wood attracts moisture through hydrogen bonding, making it physically unstable. In order to keep wood in optimal condition as long as possible, proper protection is pursued and a broad range of chemical treatments may be used. The improvement in properties of wood may also be enhanced by preparing wood polymer composites (WPCs) with "appropriate chemical treatment [5]" "Modification with suitable chemicals is an important often-followed route to improve and protect wood properties [1, 6-10]." Over the years, wood has been treated with a variety of chemicals to augment its physical, mechanical, and biological properties. Such modified wood not only is more resistant against decay but also has improved mechanical properties, in particular, strength.

Wood has many desirable characteristics required for a variety of end uses such as construction, furniture, 
and tools. A deficiency of high quality hardwoods has driven researchers and manufactures to search for alternative resources, such as softwood and some low-density hardwood, for value added application [11]. In Malaysia, especially Sarawak has the third biggest rainforest in the world. Several tropical wood species are abundantly available in Sarawak. In addition, the stock volume of tropical light hardwood is higher; however, they have not been sufficiently developed and utilized because of several drawbacks such as "low physical, mechanical, and thermomechanical properties [12]." Therefore, satisfactory use of these types of wood depends on proper treatment as specific uses of wood require exclusive treatments before they can be utilized. Suitable technologies are needed to improve wood properties specially physical, mechanical, and thermal properties in order to meet specific end-use requirements. "The formation of wood polymer composites (WPCs) is one of the promising approaches to achieve this target [13]."

Lately, interest has been manifested in wood impregnation with a variety of monomers such as styrene, epoxy resins, urethane, phenol formaldehyde, methyl methacrylate (MMA), vinyl, and acrylic monomer to improve the negative properties in wood [14]. WPC made with combinations of monomers like hexadiol, diacrylate, hydroxyethyl methacrylate, glycidyl methacrylate, hexamethylene diisocyanate, and anhydride has been shown to improve the dimensional and thermal stability [15]. However, it is generally known and accepted that most of the monomers do not react or form bond with the reactive groups of the wood fibers but instead simply bulk the void spaces within the wood structure. Many polymers, even though formed in situ, only fill the empty lumens in the wood, which leads to a mixture of two materials rather than a real composite. Accordingly, the resulting products are still subjected to changes in their physical and chemical properties with environmental factors. It can therefore be deduced that if bonding/reaction occur between the chemical and the hydroxyl groups on the cellulose fibers, the physical properties of treated wood may be further improved [16].

"Polyvinyl alcohol (PVA) has widely been used as a crosslinking agent to produce biodegradable polymer matrix compounds $[17,18]$." It has also been used as a decharacterizing agent of thermosetting resin and as a binding agent such as carbamide, formaldehyde resi, and melamine, for plywood, artificial board, and timber processing. "PVA is a highly hydrophilic polymer that can be modified with vinyl monomers to obtain copolymers (PVA-co-MMA) with improved properties [19]." It was also renowned that the functionalized PVA was easily copolymerized and/or crosslinked with acrylic acid or its partially neutralized form to give crosslinked polymeric matrix. MMA monomer was chosen along with PVA to form copolymer. MMA is cheap, available, and it can be easily polymerized and impregnated into other materials. A large number of research studies have been conducted on "chemical modification and characterization of wood [20, 21]." Very little or no work, however, has been devoted to Malaysian tropical light hardwood species and their chemical treatment with the "combination of two monomers-methyl methacrylate (MMA) and polyvinyl alcohol (PVA) [12]."

In the present work, five species of selected Malaysian tropical light hardwood were utilized as starting materials as they are easily obtainable in the local forest. The major drawbacks of these species include their high moisture uptake, biodegradation, and physicomechanical property changes with environmental variations. These drawbacks limit the use of these species. It has been established that the hydrophilic nature responsible for moisture sorption causes swelling, fungal attack, and deformation of the product $[2,5]$. The physical, mechanical, and biological property changes of wood can be minimized by suitable chemical treatment, which is a promising way to improve wood properties [1-3]. In order to overcome the aforementioned problems, wood species were chemically treated with a combination of MMA/PVA mixture where PVA was used as a copolymer agent. Therefore, the main objectives of this research are to manufacture WPC from selected tropical wood species by means of MMA and PVA prepolymer mixture and to investigate their physical, mechanical, and thermal properties.

\section{Materials and Methods}

2.1. Materials. Tropical light hard wood species Jelutong (Dyera costulata), Terbulan (Endospermum diadenum), Batai (Paraserianthes moluccana), Rubberwood (Hevea brasiliensis), and Pulai (Alstonia pneumatophora) were collected from the local forest of Sarawak, Malaysia. The densities of these tropical wood species are $380,450,455,480$, and $650 \mathrm{~kg} / \mathrm{m}^{3}$ for Batai, Jelutong, Pulai, Terbulan, and Rubberwood, respectively. Chemicals used for wood specimens treatment were methyl methacrylate (MMA) and polyvinyl alcohol (PVA). MMA and PVA have a density of $0.942-0.944 \mathrm{~g} / \mathrm{cm}^{3}$ and $1.19-1.31 \mathrm{~g} / \mathrm{cm}^{3}$, respectively, and both are analytical grade products of Merck, Germany.

2.2. Specimen Preparation. The sapwood portions of wood were cut into three bolts of $1.2 \mathrm{~m}$ in length. Each part was quarter sawn to produce planks of $4 \mathrm{~cm}$ thickness. Then they were subsequently conditioned to air-dry in a room with relative humidity of $60 \%$ and at ambient temperature of $25^{\circ} \mathrm{C}$ for six months prior to testing. The clear, defect-free planks were ripped and sized to $300 \mathrm{~mm}(\mathrm{~L}) \times 20 \mathrm{~mm}(\mathrm{~T}) \times 20 \mathrm{~mm}$ $(\mathrm{R})$ and $60 \mathrm{~mm}(\mathrm{~L}) \times 20 \mathrm{~mm}(\mathrm{~T}) \times 20 \mathrm{~mm}(\mathrm{R})$ samples for three-point bending and water absorption test, respectively. Powder samples were prepared for thermogravimetric (TGA) test.

2.3. Preparation of Prepolymer Mixture. In order to prepare prepolymer mixture, $10 \%(\mathrm{wt} / \mathrm{wt})$ polyvinyl alcohol (PVA) and $2 \%$ benzyl peroxide catalyst were added into the methyl methacrylate (MMA) monomer at a mixing speed of $3050 \mathrm{rpm}$ for 20 minutes in a disintegrator to form suspensions. Those specimens were subsequently used to impregnate the wood samples under specific conditions. 
2.4. Manufacturing of Wood Polymer Composite (WPC). For wood polymer composite (WPC) manufacturing, test samples were placed in an impregnation vacuum-chamber and a maximum vacuum $(10 \mathrm{kPa})$ was drawn on the wood for 30 minutes. The respective prepolymer mixture at full loading was introduced into the chamber until the samples were entirely covered. The samples were then soaked in prepolymer solution for 6 hours at ambient temperature and atmospheric pressure to obtain further impregnation. Finally, the samples were wrapped with aluminum foil and placed in an oven for 24 hours at $105^{\circ} \mathrm{C}$ for polymerization to take place and then weighed to determine weight percentage gain (WPG) according to

$$
\mathrm{WPG}(\%)=\frac{\left(W_{i}-W_{f}\right)}{W_{i}} \times 100,
$$

where $W_{i}$ and $W_{f}$ are oven-dried weight of raw wood and fabricated WPC samples, respectively.

2.5. Determination of Moisture Content. The untreated and treated wood samples were oven-dried at $103^{\circ} \mathrm{C}$ for $24 \mathrm{~h}$. They were then placed in a conditioning chamber at a temperature of $22^{\circ} \mathrm{C}$ and a relative humidity of $65 \%$ for approximately 6 weeks. After stabilization, the weight of each sample was measured. The moisture content (MC) at equilibrium (2) was calculated as follows:

$$
\operatorname{MC}(\%)=\frac{\left(M_{2}-M_{1}\right)}{M_{1}} \times 100,
$$

where $M_{2}$ is the weight of the raw wood at moisture absorption equilibrium and $M_{1}$ is the oven-dried weight of the untreated or treated wood sample.

2.6. Fourier Transform Infrared Spectroscopy (FTIR). The infrared spectra of the untreated and treated grounded powder wood samples were recorded on a Shimadzu Fourier transform infrared spectroscopy (FTIR) 81001 spectrophotometer. The transmittance range of scan was from 370 to $4000 \mathrm{~cm}^{-1}$. The obtained spectra are described in the Results and Discussion section.

2.7. X-Ray Diffraction (XRD). In order to assess the morphological properties of WPC, XRD analysis was applied. A PANalytical XRD diffractometer was used where $\mathrm{Cu} K \alpha(\lambda=$ $1.54 \AA$ Á) radiation was employed with $2 \theta$ varying between $4^{\circ}$ and $80^{\circ}$ at $5^{\circ} / \mathrm{min}$. The crystalline-to-amorphous ratio of materials was determined using

$$
\operatorname{Cr} . \mathrm{I}(\%)=\frac{\left(I_{002}-I_{\mathrm{am}}\right)}{I_{002}},
$$

where Cr.I is the crystallinity index, $I_{002}$ is the maximum intensity (in arbitrary units) of the diffraction from the 002 plane at $2 \theta=22.8^{\circ}$ and $I_{\mathrm{am}}$ is the intensity of the background scatter measured at $2 \theta=19.8^{\circ}$.
2.8. Scanning Electron Microscopy (SEM). The interfacial bonding between the cell wall polymer and monomer mixture was examined using a scanning electron microscope (JSM-6701F) supplied by JEOL Company Limited, Japan. The specimens were first fixed with Karnovsky's fixative and then taken through a graded alcohol dehydration series. Once dehydrated, the specimen was coated with a thin layer of gold before viewing on the SEM. The micrographs were taken at different magnifications and are presented in the Results and Discussions section.

2.9. Water Absorption Test. To determine the water uptake, the water absorption tests of the untreated and treated wood specimens were carried out according to ASTM D 570-99 and the increase in the weight of the specimens was calculated using (3):

$$
\begin{aligned}
\text { Water absorption }(\%)= & \frac{\text { Final weight }- \text { Original weight }}{\text { Original weight }} \\
& \times 100 .
\end{aligned}
$$

2.10. Bending and Compression Test. In order to mechanically characterize manufactured composites, bending and compression tests were carried out according to ASTM D-143 using a Shimadzu universal testing machine having a loading capacity of $300 \mathrm{kN}$. A crosshead speed of $2 \mathrm{~mm} / \mathrm{min}$ was used during the tests.

2.11. Thermogravimetric Analysis (TGA). TGA measurements were carried out on 5-10 mg of raw and their composites (powder samples) at a heating rate of $10^{\circ} \mathrm{C} / \mathrm{min}$ in a nitrogen atmosphere using a thermogravimetric analyzer (TA Instrument SDT Q600). WPC and raw wood were subjected to TGA in high purity nitrogen under a constant flow rate of $5 \mathrm{~mL} / \mathrm{min}$. Thermal decomposition of each sample occurred in a programmed temperature range of 30$800^{\circ} \mathrm{C}$. The continuous weight loss and temperature were recorded and analyzed to determine the following TGA parameters: thermal degradation rate (\% weight loss/min), initial degradation temperature, and residual weight (RW) at $800^{\circ} \mathrm{C}$.

\section{Results and Discussion}

3.1. Weight Percentage Gain (WPG\%) Results. After impregnation with MMA/PVA, the weight percentage gains for Jelutong, Terbulan, Batai, Rubberwood, and Pulai were 42, $38,47,25$, and 32\%, respectively. These results revealed that MMA/PVA were successfully incorporated in the wood species in order to form wood polymer composites. Among the wood species used, Batai wood gained highest amount of polymer compared to the other ones. This indicates that the WPG of wood samples were dependent on the density of wood species [12]. This is expected because lower density wood species gained higher amount of polymer and vice versa. 


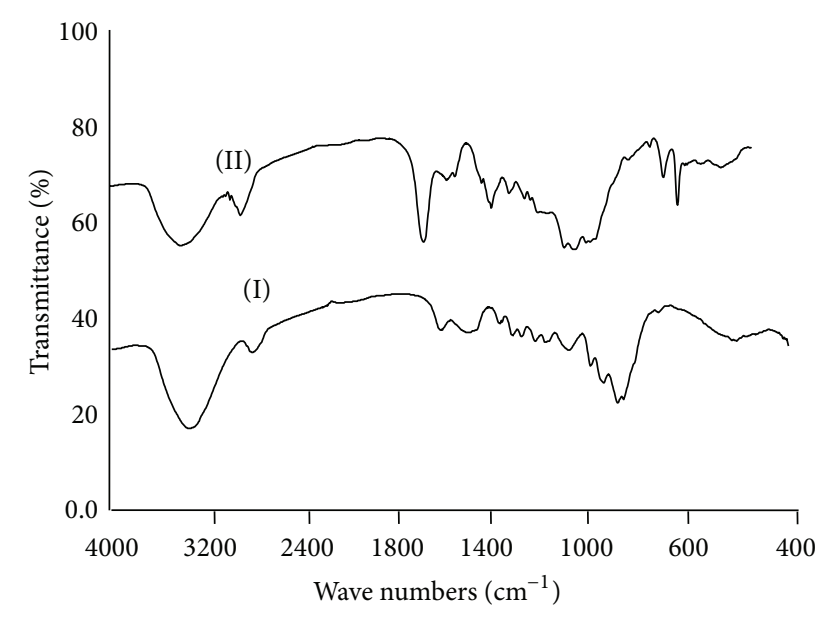

FIGURE 1: FTIR spectrum of (I) raw Jelutong wood and (II) treated Jelutong wood.

3.2. Moisture Content Test Results. The moisture content of raw wood and WPC samples was $11,12,10,13$, and $14 \%$ and $6,7,5,9$, and 5\% for Jelutong, Terbulan, Batai, Rubberwood, and Pulai, respectively. All raw wood samples exhibited a higher percentage of moisture absorption than the modified WPCs. This was expected because cell walls with hydrophilic hydroxyl groups will absorb moisture to its surface through the formation of hydrogen bonding [22]. However, it was found that after impregnation with MMA/PVA, the moisture content of wood samples reduced significantly. The reduction in MC for the manufactured WPCs could be attributed to the impregnated polymer MMA/PVA, which may block sorption sites in the interior of wood cell lumens and the cell wall [23]. Consequently, a few water sorption sites remain, which also contributed to the reduction in water uptake. "The similar result was also reported by the other researchers [22, 23]".
3.3. Fourier Transform Infrared Spectroscopic (FTIR) Analysis. In order to investigate the interaction between wood, MMA, and PVA, FTIR test was carried out. The spectrum analysis of the raw wood and WPC is shown in Figure 1. The FTIR spectrum of the raw wood perceptibly showed the characteristic absorption band in the region of $3418 \mathrm{~cm}^{-1}$, $1736 \mathrm{~cm}^{-1}$, and $2933 \mathrm{~cm}^{-1}$ due to $\mathrm{O}-\mathrm{H}, \mathrm{C}=\mathrm{O}$, and $\mathrm{C}-\mathrm{H}$ stretching vibration, respectively. These absorption bands are due to hydroxyl group $(-\mathrm{OH})$ in cellulose, carbonyl group of acetyl ester in hemicellulose, and carbonyl aldehyde in lignin [24]. Conversely, it can be seen from Spectrum (II) that the peak was at $1736 \mathrm{~cm}^{-1}$, which is due to carbonyl stretching vibration, shifted towards higher wave number with high peak intensity upon impregnated with MMA/PVA monomer mixture. It can also be distinguished that the C$\mathrm{H}$ stretching vibration peaks (at $2933 \mathrm{~cm}^{-1}$ ) were transferred in the direction of higher wave number (at $2980 \mathrm{~cm}^{-1}$ ) with spacious band intensity in the FTIR spectrum of WPC (Spectrum II). Moreover, there were two new peaks clearly appearing at $700 \mathrm{~cm}^{-1}$ and $720 \mathrm{~cm}^{-1}$ in Spectrum II, which are due to the $-\mathrm{CH}_{2}$ bending and $\mathrm{C}-\mathrm{H}$ stretching vibration in the WPC. Therefore, it can be confirmed that MMA reacted with hydroxyl group $(-\mathrm{OH})$ of wood and polymerized with PVA, thus forming wood-MMA-PVA compound $[19,25]$. The absorption band of $\mathrm{O}-\mathrm{H}$ group also shifted towards higher wave number $\left(3408 \mathrm{~cm}^{-1}\right.$ to $\left.3426 \mathrm{~cm}^{-1}\right)$ with narrowed band intensity, which gives further evidence of the reaction and copolymerization between wood, MMA, and PVA [26]. These results confirmed that PVA provided better interface interaction between the wood fiber surfaces and MMA, which significantly increased the other properties of WPC. All these, as stated above, confirmed the following reaction.

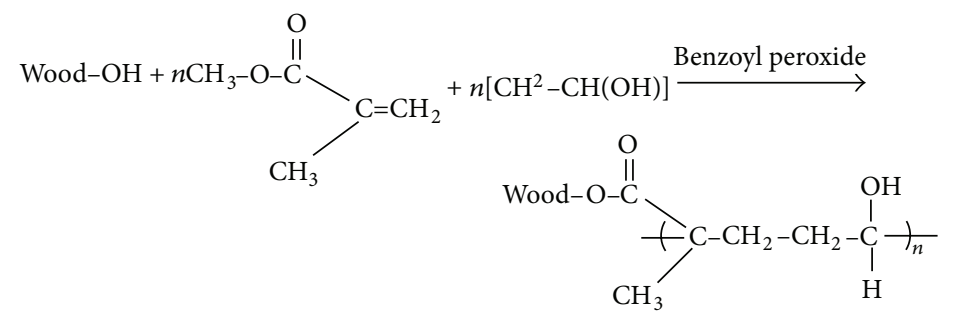

3.4. XRD Analysis. The X-ray diffraction patterns of raw wood and WPC are given in Figures 2(I) and 2(II). It can be seen from Figure 2(I) that the patterns of raw wood fibers exhibit three well-defined peaks $(2 \theta)$ at $15.1,22.8$, and $34.7^{\circ}$, which correspond to the (110), (200), and (023) or (004) crystallographic planes, respectively $[27,28]$. The pattern also indicated that the raw wood consists mainly of diffuse peaks. This proves that the wood is an extremely poor crystalline material [27].
Conversely, it was observed that there were three new peaks $(2 \theta)$ at $35.2^{\circ}, 45.5^{\circ}, 54.3^{\circ}$, and $73.8^{\circ}$ of high intensity in the amorphous region of $40^{\circ}$ to $80^{\circ}$ in the XRD pattern in Figure 2(II). These new peaks may be due to the interaction of MMA, wood, and PVA and the formation of wood composites. Additionally, the crystallinity of the samples was measured based on the 002 plane and peaks at $2 \theta=22.8^{\circ}$. The crystallinity values of raw wood and WPC were $25.8 \%$ and $39.8 \%$, respectively. This indicates that the crystallinity values 


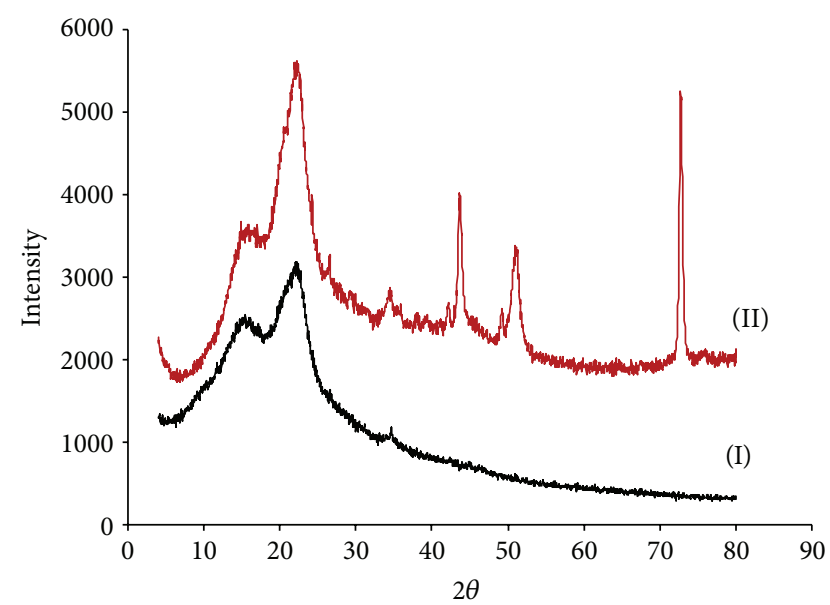

FIGURE 2: Typical XRD patterns of (I) raw wood and (II) WPC.

of WPC were significantly increased (14\%) compared to raw wood for the peaks $(2 \theta)$ at $=22.8^{\circ}$.

The copolymer PVA-co-MMA reacted with $\mathrm{OH}$ groups of wood and formed wood-PVA-co-MMA, which enhanced the crystallinity of WPC. This result indicates that the PVA-coMMA significantly increased the crystallinity of WPC samples. Similar results are also reported by the other researchers [29].

3.5. Scanning Electron Microscopic (SEM) Analysis. The typical (Jelutong wood) SEM of raw and WPC samples was shown in Figures 3(a) and 3(b) in transverse section. The raw wood in Figure 3(a) clearly shows the number of void spaces and agglomerations of fiber in the wood surface, which are removable with suitable chemical treatment $[1$, 16]. Figure 3(b) shows clean and completely polymer filled void spaces throughout the wood surface. It is also clear that the filling behavior of PVA-co-MMA was in interaction with the outside surface of the cell lumens as well, because the combined monomer mixture was polymerized homogeneously. This might be due to the strong interface interaction between wood, PVA, and MMA in which PVA acted as a crosslinker. This is also anticipated because PVA reacts with wood hydroxyl group and copolymerized with MMA and produced wood-PVA-co-MMA which enhances the adhesion and compatibility of polymer to cell wall and vessels of the wood. This result recommended that the copolymerization created a strong interface with wood cell walls, accounting for the observed increase in mechanical strength and thermal stability [11].

3.6. Modulus of Elasticity (MOE). The modulus of elasticity (MOE) of raw wood and WPC samples is shown in Figure 4. It can be seen from Figure 4 that the MOE of WPC samples has been increased compared to their corresponding raw samples. The MOE of WPC of Jelutong showed the highest increment after treatment with MMA/PVA, followed by Rubberwood, Pulai, Batai, and Terbulan, respectively. The higher MOE of WPC samples compared to the raw wood was due to the chemical modification, which is in accordance with other research findings [30]. The increase in the MOE value of WPC compared to the raw wood samples was due to the presence of PVA, which reacted and copolymerized with MMA and wood providing better adhesion and interaction among the polymers [15]. In the wood specimens, the MMA/PVA polymer completely filled all the void spaces in the wood and thus enhanced the MOE value of WPC samples. This improvement in MOE was also supported by XRD and SEM study.

3.7. Compressive Modulus. Figure 5 demonstrates the compressive modulus parallel to the grain for raw wood and WPC samples. From Figure 5, it is apparent that there was a considerable increase in compressive strength for MMA/PVA impregnated WPC samples. Among the five wood species used, the highest increase in compressive strength was observed in Batai, followed by Jelutong, Terbulan, Pulai, and Rubberwood, respectively. Raw wood species failed in compression because of the bulking of relatively thin cell walls due to a long column type of instability [12,13]. It is well known and acknowledged that the lateral stability of wood samples has been enhanced with the presence of polymer in the cell wall of wood [13]. This has been predicted because PVA has the ability to increase the adhesion and compatibility between the wood cell wall and MMA, thus forming a strong polymer coating on its surface. Consequently, the lateral stability of the cell wall was enhanced. Similar results have also been observed by previous researchers [30].

3.8. Water Absorption Test Results. Figure 6 displays the result of water absorption properties of raw wood and WPC samples. All raw wood specimens exhibited higher percentage of water absorption compared to the MMA/PVA impregnated WPC samples. This result is expected because cell wall hydrophilic hydroxyl groups of wood absorbed water to its surface through the formation of hydrogen bonding [15]. The WPC of Rubberwood had the highest decrement in water absorption, followed by Jelutong, Batai, Terbulan, and Pulai, respectively. The decrease in water absorption for MMA/PVA treatment has also been expected because PVA reacted and copolymerized with MMA and numerous hydroxyl groups contained in wood components, as stated earlier. Hence, fewer water absorption sites remained, which also contributed to the reduction in water uptake [22].

3.9. Thermogravimetric Analysis (TGA). Figure 7 shows the typical (Jelutong wood) TGA thermograms of raw and WPC samples. Important data derived from each thermogram are explained briefly in Table 1 . As seen in Figure 7 and Table 1, the initial decomposition temperature $\left(T_{i}\right)$ for the raw samples is typical of wood in which decomposition of wood components took place below $250^{\circ} \mathrm{C}[30,31]$. In contrast, the initial decomposition temperature $\left(T_{i}\right)$ and the maximum decomposition temperature $\left(T_{f}\right)$ values for WPC samples were significantly higher than their corresponding raw wood samples. These results indicate that a WPC sample impregnated with MMA/PVA was more thermally stable 


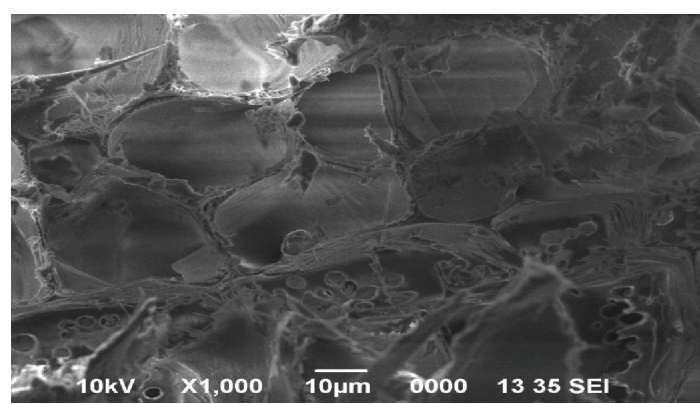

(a)

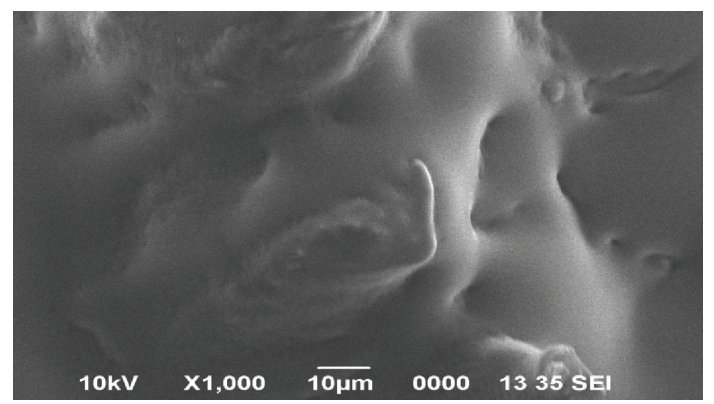

(b)

FIGURE 3: Typical SEM micrographs of Jelutong (a) raw wood and (b) WPC sample.

TABLE 1: TGA results of raw wood and WPC samples.

\begin{tabular}{|c|c|c|c|c|c|}
\hline \multicolumn{2}{|c|}{ Wood species and sample particulars } & ${ }^{\mathrm{a}} T_{i}\left({ }^{\circ} \mathrm{C}\right)$ & ${ }^{\mathrm{b}} T_{m}\left({ }^{\circ} \mathrm{C}\right)$ & ${ }^{\mathrm{c}} T_{f}\left({ }^{\circ} \mathrm{C}\right)$ & $\mathrm{RW}(\%)$, at $800^{\circ} \mathrm{C}$ \\
\hline \multirow{2}{*}{ Jelutong } & Raw wood & 230.69 & 351.97 & 367.87 & 24.12 \\
\hline & WPC & 258.12 & 402.33 & 438.30 & 16.40 \\
\hline \multirow{2}{*}{ Terbulan } & Raw wood & 242.19 & 355.48 & 383.16 & 27.23 \\
\hline & WPC & 273.22 & 393.35 & 447.67 & 20.76 \\
\hline \multirow{2}{*}{ Batai } & Raw wood & 242.24 & 305.12 & 390.68 & 22.14 \\
\hline & WPC & 277.56 & 320.45 & 476.27 & 17.20 \\
\hline \multirow{2}{*}{ Rubberwood } & Raw wood & 250.00 & 320.20 & 390.82 & 27.32 \\
\hline & WPC & 274.74 & 368.30 & 442.35 & 22.50 \\
\hline \multirow{2}{*}{ Pulai } & Raw wood & 242.34 & 305.10 & 381.11 & 17.54 \\
\hline & WPC & 257.37 & 322.45 & 410.46 & 13.55 \\
\hline
\end{tabular}

${ }^{{ }^{a}} T_{i}$ values for initial decomposition temperature.

${ }^{\mathrm{b}} T_{m}$ values for the maximum rate of mass loss.

${ }^{c} T_{f}$ values for the maximum decomposition temperature.

RW values for residual weight.

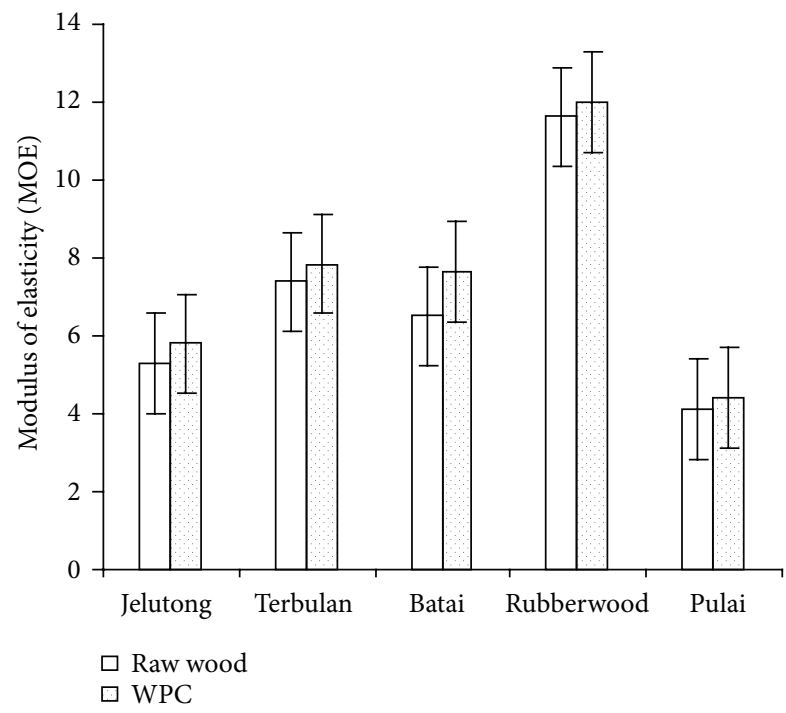

FIGURE 4: Modulus of elasticity of raw wood and WPCs.

than raw wood sample. The same phenomenon has also been reported by other researchers [32]. The incorporated

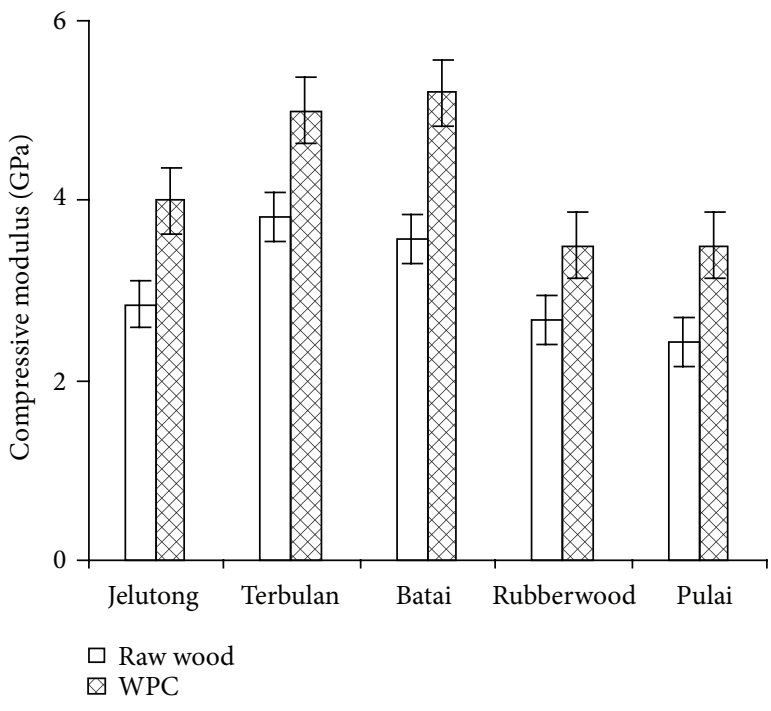

FIgURE 5: Compressive modulus of raw wood and WPCs. prepolymer mixture (MMA/PVA) was polymerized homogenously throughout the wood fiber surfaces, thus allowing stabilization and barrier effects [33]. It is considered that the 


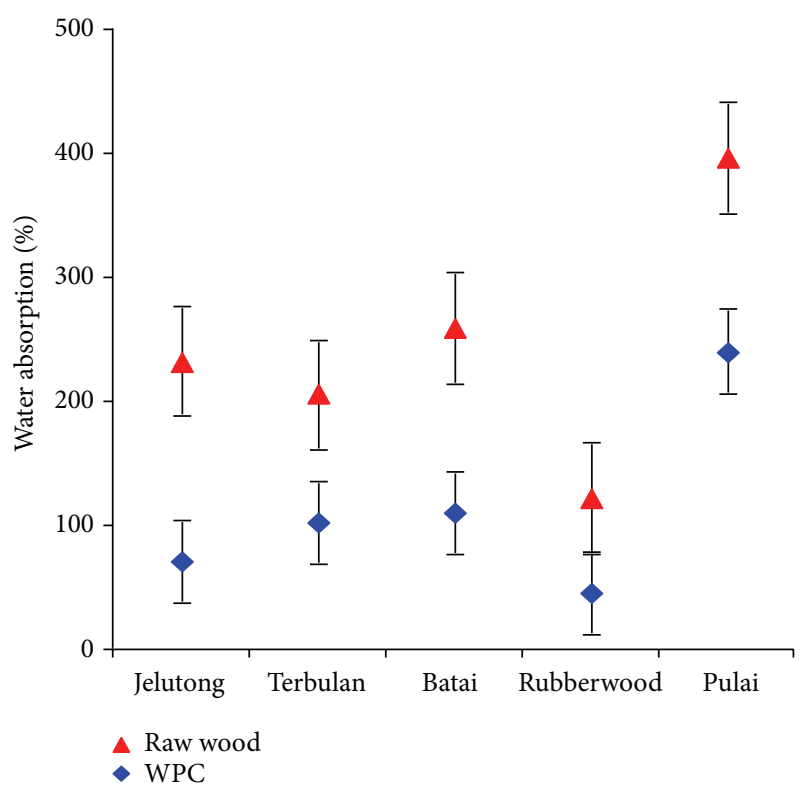

Figure 6: Average water absorption (\%) of raw wood and WPC samples.

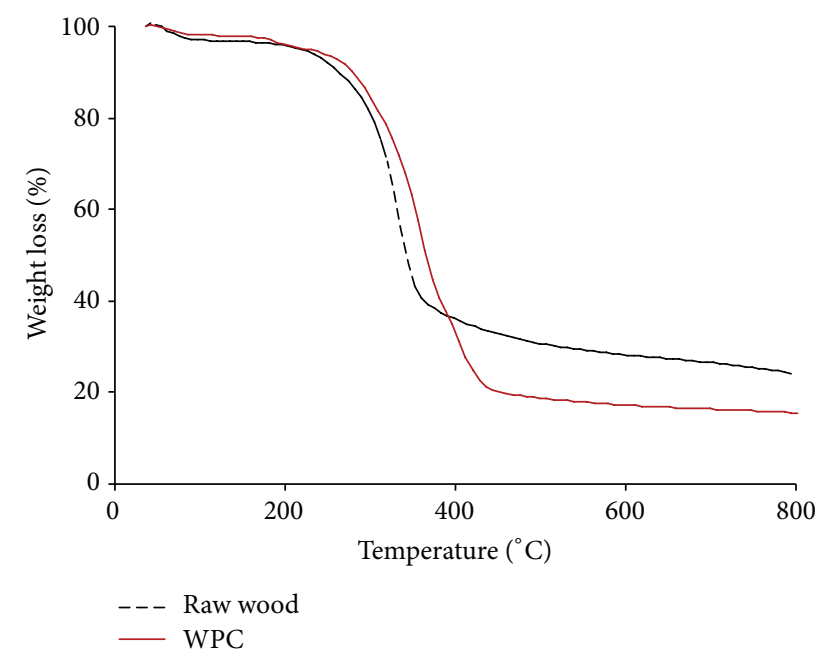

Figure 7: Typical TGA curves of raw Jelutong wood and WPC samples.

major source of this stability is due to the chemical interaction with wood fibers and new chemical bonding, which allows thermal energy to be distributed over many bonds [30].

From Table 1, it can be apparent that the general residual weight (RW) at $800^{\circ} \mathrm{C}$ of WPC samples exhibited decrement compared to the raw wood samples. This could be due to the decomposition of incorporated MMA/PVA from the surface of wood composites [32]. It was also observed that the maximum rate of mass loss $\left(T_{m}\right)$ of WPCs was higher compared to raw wood samples. This result is expected and may be due to the strong interactions between MMA, PVA, and wood, which acted as a barrier and obstructed the diffusion of decomposed volatile products throughout the composites [34]. The similar result was also reflected in the FTIR and SEM analysis. All these observations confirm the copolymerization of PVA between MMA and wood interfaces, which considerably improve the thermal stability of wood composite products [35].

\section{Conclusions}

From the present study, it can be concluded that optimistic improvement in physical, mechanical, and thermal properties was obtained for all selected woods, which were treated with PVA-co-MMA copolymer formulations. The reaction and copolymerization between wood, PVA, and MMA yielded wood-PVA-co-MMA compound. This compound was confirmed from the FTIR spectrum where the characteristic peak at $1736 \mathrm{~cm}^{-1}$ and $2933 \mathrm{~cm}^{-1}$ was shifted towards the higher wave numbers due to the interaction between wood, PVA, and MMA. For WPC, an improved degree of crystallinity was exhibited from XRD results. The MOE and compressive modulus of WPCs were shown to increase by $3-18 \%$ and $30-45 \%$ compared to their corresponding raw samples, respectively. WPC samples showed lower water absorption (39-70\%) compared to the raw samples. Furthermore, WPC samples had shown improved thermal stability over all raw wood samples. The improved wood properties could be ascribed to copolymerization and strong interaction between the wood surface, PVA, and MMA.

\section{Conflict of Interests}

The authors declare that there is no conflict of interests regarding the publication of this paper.

\section{Acknowledgment}

This research work reported in this paper has been funded by the Ministry of Higher Education, Malaysia, under the Research Project FRGS/02(05)/655/2007(20).

\section{References}

[1] R. M. Rowell, "Chemical modification of wood: a short review," Material Science and Engineering, vol. 1, no. 1, pp. 29-33, 2006.

[2] C. A. S. Hill, Wood Modification: Chemical, Thermal and Other Processes, John Wiley \& Sons, Chichester, UK, 2006.

[3] S. Kumer, "Chemical modification of wood," Wood and Fiber Science, vol. 26, pp. 270-280, 1994.

[4] R. S. Willimas, Handbook of Wood Chemistry and Wood Composite, Forest Service Forest Products Laboratory, USDA, Washington, DC, USA, 2005.

[5] A. S. Galperin, G. G. Kuleshov, V. I. Tarashkevich, and G. M. Shutov, "Manufacturing and properties of modified wood: a review of 25 years work," Holzforschung, vol. 49, no. 1, pp. 4550, 1995.

[6] N. Ozmen, N. S. Setin, P. Tanguat, and G. Sebe, "A new route for the functionalisation of wood through transesterification reactions," European Polymer Journal, vol. 42, pp. 1617-1624, 2006. 
[7] N. Ozmen and N. S. Setin, "The effect of chemical modification on the strength of wood and bonded wood joints," European Polymer Journal, vol. 38, no. 7, pp. 1483-1486, 2002.

[8] R. R. Devi, K. Gogoi, B. K. Konwar, and T. K. Maji, "Synergistic effect of nanoTiO $\mathrm{Ti}_{2}$ and nanoclay on mechanical, flame retardancy, UV stability, and antibacterial properties of wood polymer composites," Polymer Bulletin, vol. 70, no. 4, pp. 13971413, 2013.

[9] P. Wang, J. Liu, W. Yu, and C. Zhou, "Dynamic rheological properties of wood polymer composites: from linear to nonlinear behaviors," Polymer Bulletin, vol. 66, no. 5, pp. 683-701, 2011.

[10] B. K. Deka and T. K. Maji, "Effect of $\mathrm{SiO}_{2}$ and nanoclay on the properties of wood polymer nanocomposite," Polymer Bulletin, vol. 70, no. 2, pp. 403-417, 2013.

[11] M. S. Islam, S. Hamdan, Z. A. Talib, A. S. Ahmed, and M. R. Rahman, "Tropical wood polymer nanocomposite (WPNC): the impact of nanoclay on dynamic mechanical thermal properties," Composites Science and Technology, vol. 72, no. 16, pp. 1995-2001, 2012.

[12] M. R. Islam, S. Hamdan, I. Jusoh, M. R. Rahman, and A. S. Ahmed, "The effect of alkali pretreatment on mechanical and morphological properties of tropical wood polymer composites," Materials \& Design, vol. 33, no. 1, pp. 419-424, 2012.

[13] Y. Zhang, C. Yu, P. K. Chu et al., "Mechanical and thermal properties of basalt fiber reinforced poly(butylene succinate) composites," Materials Chemistry and Physics, vol. 133, no. 2-3, pp. 845-849, 2012.

[14] Ü. C. Yildiz, S. Yildiz, and E. D. Gezer, "Mechanical properties and decay resistance of wood-polymer composites prepared from fast growing species in Turkey," Bioresource Technology, vol. 96, no. 9, pp. 1003-1011, 2005.

[15] R. R. Devi, I. Ali, and T. K. Maji, "Chemical modification of rubber wood with styrene in combination with a crosslinker: effect on dimensional stability and strength property," Bioresource Technology, vol. 88, no. 3, pp. 185-188, 2003.

[16] R. M. Rowell, Handbook of Wood Chemistry and Composite, Taylor and Francis, Boca Raton, Fla, USA, 2005.

[17] T.-H. Kim and N. A. Peppas, "Preparation and characterization of poly(vinyl alcohol-co-methyl methacrylate) copolymers," Polymer Bulletin, vol. 12, no. 1, pp. 59-63, 1984.

[18] A. B. Argade and N. A. Peppas, "Poly(acrylic acid)-poly(vinyl alcohol) copolymers with superabsorbent properties," Journal of Applied Polymer Science, vol. 70, no. 4, pp. 817-829, 1998.

[19] X. Cai, B. Riedl, S. Y. Zhang, and H. Wan, "Formation and properties of nanocomposites made up from solid aspen wood, melamine-urea-formaldehyde, and clay," Holzforschung, vol. 61, pp. 148-154, 2007.

[20] M. Kazayawoko, J. J. Balatinecz, and L. M. Matuana, "Surface modification and adhesion mechanisms in woodfiberpolypropylene composites," Journal of Materials Science, vol. 34, no. 24, pp. 6189-6199, 1999.

[21] A. Pratheep Kumar, R. P. Singh, and B. D. Sarwade, "Degradability of composites, prepared from ethylene-propylene copolymer and jute fiber under accelerated aging and biotic environments," Materials Chemistry and Physics, vol. 92, no. 2-3, pp. 458-469, 2005.

[22] W. Gindl and H. S. Gupta, "Cell-wall hardness and Young's modulus of melamine-modified spruce wood by nanoindentation," Composites A: Applied Science and Manufacturing, vol. 33, no. 8, pp. 1141-1145, 2002.
[23] F. C. Williams and M. D. Hale, "The resistance of wood chemically modified with isocyanates: the role of moisture content in decay suppression," International Biodeterioration and Biodegradation, vol. 52, no. 4, pp. 215-221, 2003.

[24] M. G. S. Yap, Y. T. Que, and L. H. L. Chia, "FTIR characterization of tropical wood-polymer composites," Journal of Applied Polymer Science, vol. 43, no. 11, pp. 2083-2090, 1991.

[25] M. P. Ansell, "Wood: a 45th anniversary review of JMS papers," Journal of Materials Science, vol. 47, no. 2, pp. 583-598, 2012.

[26] M. S. Islam, S. Hamdan, I. Jusoh, M. R. Rahman, and Z. A. Talib, "Dimensional stability and dynamic Youngs modulus of tropical light hardwood chemically treated with methyl methacrylate in combination with hexamethylene diisocyanate cross-linker," Industrial Engineering and Chemistry Research, vol. 50, no. 7, pp. 3900-3906, 2011.

[27] M. A. Khan, K. M. I. Ali, and W. Wang, "Electrical properties and X-ray diffraction of wood and wood plastic composite (WPC)," Radiation Physics and Chemistry, vol. 38, no. 3, pp. 303-306, 1991.

[28] B. K. Deka and T. K. Maji, "Effect of coupling agent and nanoclay on properties of HDPE, LDPE, PP, PVC blend and Phargamites karka nanocomposite," Composites Science and Technology, vol. 70, no. 12, pp. 1755-1761, 2010.

[29] M. S. Islam, S. Hamdan, M. R. Rahman, I. Jusoh, and A. S. Ahmed, "The effect of crosslinker on mechanical and morphological properties of tropical wood material composites," Materials and Design, vol. 32, no. 4, pp. 2221-2227, 2011.

[30] S. Islam, S. Hamdan, R. Rahman, I. Jusoh, A. S. Ahmed, and M. Idrus, "Dynamic young's modulus, morphological, and thermal stability of 5 tropical light hardwoods modified by benzene diazonium salt treatment," BioResources, vol. 6, no. 1, pp. 737750, 2011

[31] M. G. S. Yap, Y. T. Que, L. H. L. Chia, and H. S. O. Chan, "Thermal properties of tropical wood-polymer composites," Journal of Applied Polymer Science, vol. 43, no. 11, pp. 2057-2065, 1991.

[32] R. R. Devi and T. K. Maji, "Effect of nano- $\mathrm{SiO}_{2}$ on properties of wood/polymer/clay nanocomposites," Wood Science and Technology, vol. 46, no. 6, pp. 1151-1168, 2012.

[33] Q. K. Meng, M. Hetzer, and D. de Kee, "PLA/clay/wood nanocomposites: nanoclay effects on mechanical and thermal properties," Journal of Composite Materials, vol. 45, no. 10, pp. 1145-1158, 2011.

[34] G. Das and N. Karak, "Vegetable oil-based flame retardant epoxy/clay nanocomposites," Polymer Degradation and Stability, vol. 94, no. 11, pp. 1948-1954, 2009.

[35] S. Mondal, P. Memmott, L. Wallis, and D. Martin, "Physicothermal properties of spinifex resin bio-polymer," Materials Chemistry and Physics, vol. 133, no. 2-3, pp. 692-699, 2012. 

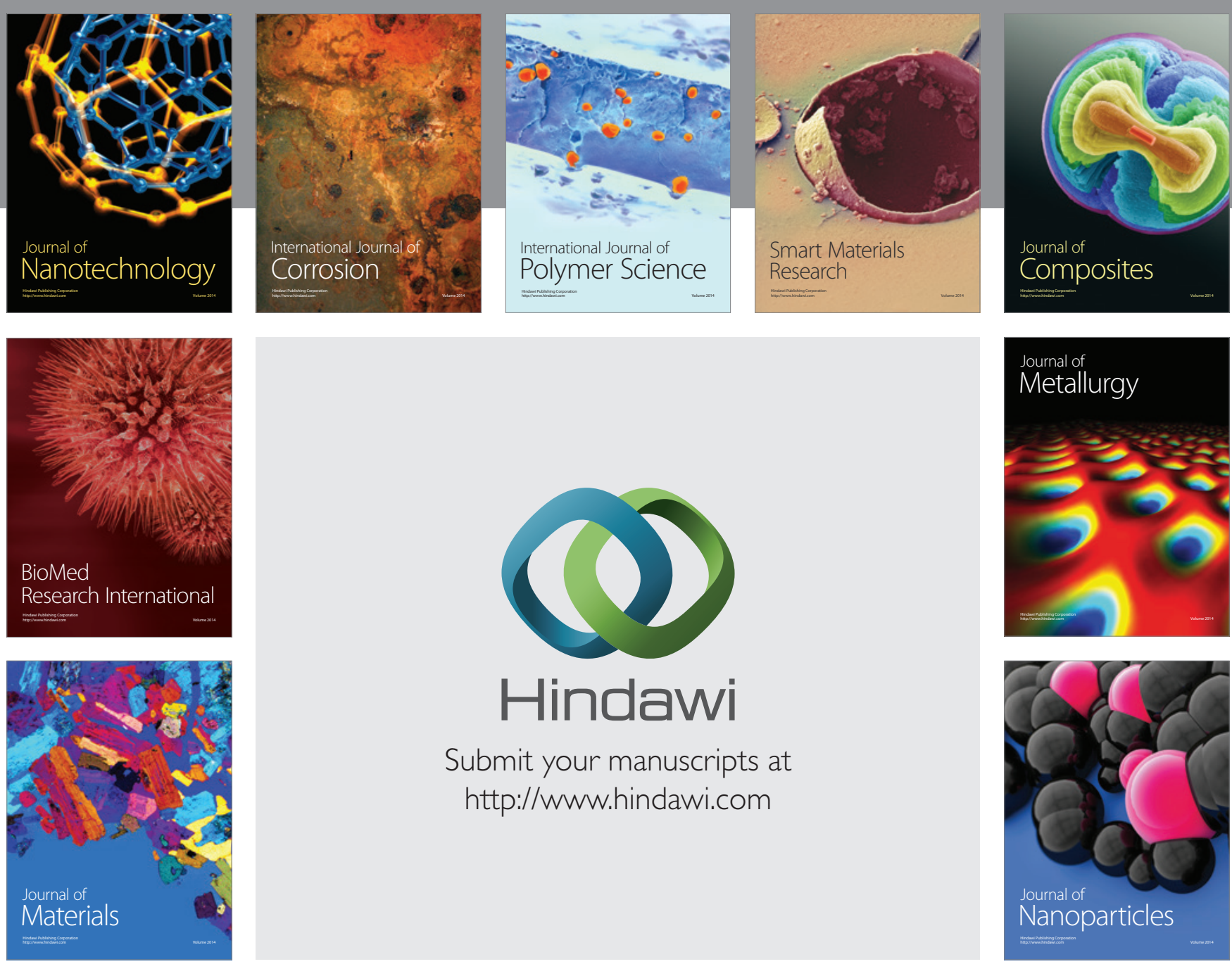

Submit your manuscripts at http://www.hindawi.com
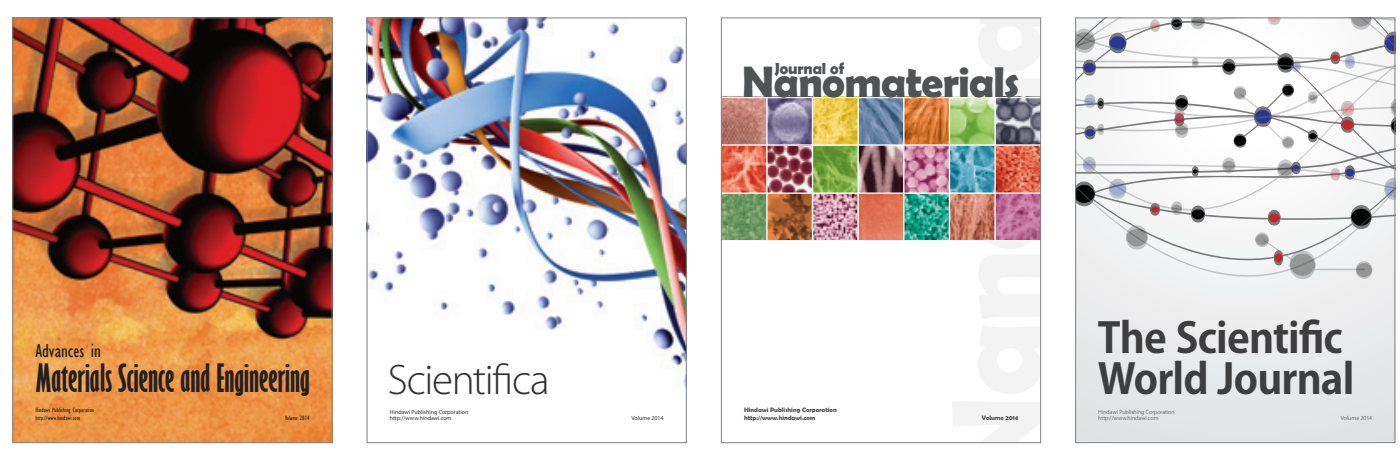

\section{The Scientific World Journal}
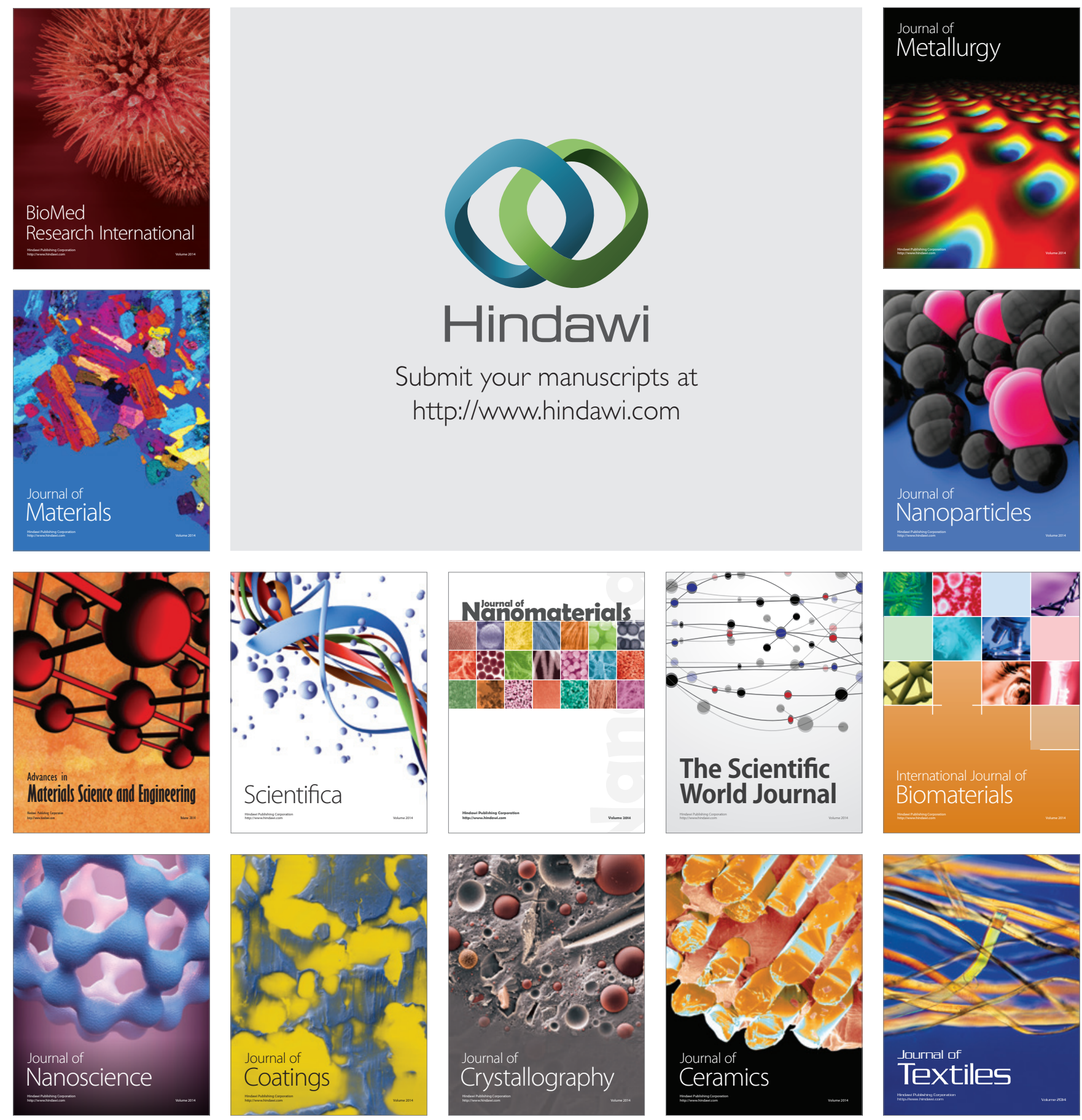